\title{
A 'Consultation' Workshop for Child Psychiatrists in Training
}

Peter Reder, Consultant Child and Family Psychiatrist; and Ken Israelstam, Clinical Assistant in Child and Family Psychiatry, Child and Family Psychiatry Department, Charing Cross Hospital, 2 Wolverton Gardens, London W6

Child psychiatrists-in-training must become conversan with a range of inter-personal skills-psychotherapy, family therapy, management, consultation-in addition to their traditional expertise of assessment, differential diagnosis and psychiatric treatments in different settings. In the Riverside training scheme we have introduced a Consultation Workshop to help trainees learn this essential art, for although it is said to be practised widely it has seldom been taught systematically. This is a report from the first 18 months of the Workshop's studies.

\section{The workshop model of training}

A workshop is a group of defined membership, meeting regularly, to study a specific topic or skill. The mode of study can vary, at any one time being didactic, experiential, literature-reviewing, and may include watching a videotape or case discussion. Our Workshop did not have a syllabus as such, although we compiled a comprehensive reading list, ${ }^{*}$ and flexible scheduling allowed members to bring pressing cases for group supervision or to refine clinical skills through repeated experiential exercises.

The Workshop setting differs from team meetings because its task is learning, rather than decision-taking and planning case management. The Workshop involves group participation and is thus time-saving and it brings together colleagues from various backgrounds to a common task of mutual learning which can benefit enormously their multidisciplinary team work. Membership of our Workshop has included psychiatrists, psychologists, a child psychotherapist, and a social worker. Child psychiatrists come to appreciate the skills of other disciplines-and vice versaand to integrate academic learning with clinical experience in which the focus is on 'process' and interaction. Our Workshop meets for an hour and a quarter every fortnight.

\section{Conceptual and clinical framework}

The Workshop studied the literature on consultation as seen from a number of perspectives-psycho-analytic, group analytic, liaison psychiatry, etc. The framework we found most useful is the systemic one grounded in Gregory Bateson's work. ${ }^{1}$ In essence, each element of a system is seen

- A copy of the Workshop reading list may be obtained from Dr Peter Reder, Department of Child and Family Psychiatry, Charing Cross Hospital, 2 Wolverton Gardens, London W6. to affect the others in a circular fashion: i.e., A influences B which feedsback to influence $A$, and so on. Problems are analysed as arising from patterns of mutual interaction, rather than A unilaterally causing B's behaviour. Bateson emphasises that an observer of a system becomes an element of that which is observed and thereby changes the observed phenomena. A consultant is always in a dilemma of observing and commenting on a process in which he/she is now a participant, so that the art of consultation is to be aware of this dilemma and remain as objective as possible.

The Workshop also found useful the work of Maturana, ${ }^{2}$ since he reinforces Bateson's warnings about observer objectivity. Furthermore, he rejects the notion that we can instruct others how to behave from a hierarchical position, but instead can engage in a 'conversation' with them and help them see the problem from a new perspective.

Bateson's and Maturana's ideas have been elaborated clinically by the Milan Associates ${ }^{3}$ and we modified the main elements of their work as a basis for our studies in consultation. We reformulated the elements as follows:

(1) Impartiality and objectivity, a stance which alerts the consultant to avoid taking responsibility for the problem, both managerially and emotionally, to avoid talking down to the consultee, and to avoid taking sides (and possibly fuelling the problem rather than helping resolve it).

(2) Information gathering, within an interactional framework, about the nature of the presenting problem and the system in which it has arisen, i.e. obtaining a systemic 'map'.

(3) Generating ideas, based on the information obtained at the point of referral or through later direct discussion with the consultee/s, which attempt to explain how the specific problem has arisen in that particular system at this time.

(4) Reaching a consensus, about who will do what next, whether the new ideas generated during the consultating conversation are useful, etc.

The Workshop repeatedly confirmed the value of at least two colleagues working together as a team in order to improve objectivity and generate ideas. Teamwork was practised frequently through role-play and simulated interviews-and, of course, the Workshop itself was available as a 'team' for the discussion of complex cases. 


\section{Consultation}

In the first meeting we discussed our understanding of the term 'consultation', guided by preparatory reading of introductory texts. We saw consultation as an indirect approach to problem-solving in which the consultee retains responsibility for managing and conducting the direct clinical work. It involves a conversation between the consultee and consultant in a non-hierarchical relationship. The relationship is initiated when the consultee nominates a problem and requests help to solve it. Usually the request arises when the consultee experiences an impasse in his work. The aim of consultation is to free the consultee to utilise his skills more effectively again, by trying to understand the process leading to an impasse in the work from a new perspective.

The Workshop explored consultation as conducted in three different settings; to an individual worker about a specific case; to a network of professionals involved in the same case; and to the staff of a unit or institution about their work.

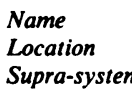

Supra-system.

a) Parent organisation

(b) Funding

(c) Relationships with other agencies Aims:

(a) As seen by others

(b) As seen by the system Membership

Hierarchy/Leadership:

(a) Overt, i.e. leadership structure

(b) Covert influence

Organisation of who does what

Sub-systems:

(a) Overt, e.g. tasks, decision-taking

(b) Covert, e.g. alliances

'Rules':

(a) Overt

(b) Covert

(c) Sanctions against breaking them

Channels of communication:

(a) Across boundary of system

(b) Within system

Historical patterns:

(a) e.g. Changes in staffing, aims, relationships, etc.

(b) How staff enter and leave

(c) Flexibility to change

Fig. 1. Map of a system

Although the mode of consulting in these three settings is different, each is guided by the process of 'systemic mapping'. In the second Workshop meeting we debated about the information required to produce a systemic map (Fig. 1).

We discussed some of the practical implications of the map, for example the need to respect a consultee's system's hierarchy and gain appropriate permission for the consultation from the head of a unit, or also inviting a social worker's senior to a consultation meeting.
A locum consultant spoke to our senior registrar as a delegate from another hospital department about possible liaison. In the following Workshop we completed a systemic map for that Department and the nominated problem. We discovered a number of discrepancies which might lead to failure in the liaison: for example, we noted that a temporary locum had raised the problem with our trainee and we eventually hypothesised that the locum was a 'triangulated' mediator between his department's two other consultants who were in a struggle for supremacy. This suggested that the liaison would need to be negotiated with all three consultants and probably would have been doomed by an alliance with the locum.

The clinical team received a request from a hospital social worker to attend his case conference about a child recently discharged from the paediatric ward. The social worker was worried about the child but unsure how to proceed. Our registrar attended with a brief to note the process of the conference as well as its content. He later reported back to the Workshop and we analysed the map as it emerged. We saw how the workers were paralysed in making clear plans because they were in a dilemma about 'ownership' of the case: for example, although the child was no longer an inpatient, the conference was held in the paediatric department, yet called and chaired by the social worker. When the paediatrician eventually arrived he had tried to take over the meeting which, not surprisingly, ended inconclusively. However, the Workshop felt that our registrar had not been in a position to comment on the process and thereby help the conference.

Consultation to an individual worker In clinical practice consultation begins from the moment that a team member picks up the telephone to receive a referral. The Workshop rehearsed this using role plays of known cases. Two Workshop participants sat back-to-back with an imaginary telephone line between them, one playing the role of anxious referrer, the other as team consultant. The task of the consultant was to receive the message and respond in such a way as to contain the anxiety, process the important data, and work towards a mutually-agreed plan of action.

A psychologist in the team had taken a telephone referral earlier in the day from a paediatric registrar, who was clearly anxious about an adolescent thought to be showing "hysterical fits". Our psychologist had been unhappy about his response and asked to use the Workshop to review the experience. He played the part of the 'referrer' since he held the information about the case. The role play evolved in a similar way to the actual telephone conversation with the 'consultant' asking more and more questions and the 'referrer' becoming ever more anxious. The Workshop then discussed alternative possible scenarios.

We learned a number of lessons from the exercise. First, a member of the clinical team should always be available to 
speak directly to a referrer and $s /$ he should be receptive to, and accepting of, the referrer's anxiety and be prepared to listen with concern to his/her story: he could say, for example, "I can see how that must have been very difficult for the ward staff". We saw how the referrer can experience a series of questions as distancing and rejecting and so they should be prefaced by an explanation: for example, "I'd like to work out with you the best way for me to help, and so I shall need to know some more details.... A referrer's anxiety can be transmitted to the consultant and we decided it could be useful to 'break the spell' by asking him to hold the line, while the consultant thought for a moment, or found a team colleague with whom to discuss the problem. It became clear that the consultant should end the conversation with a firm action-plan, for example saying, "I'm sorry that no one can come to the ward immediately as you have asked, but I would like you to arrange for the parents to be there at three o'clock and before I see the family I would like to speak with the nursing staff....".

A worker can become so involved in his case that he no longer can 'see the wood for the trees': sometimes he refers on for yet another assessment or a different treatment. Consultation can help him process information he already has, or review whether the different treatment would, in fact, be helpful.

A social worker telephoned the clinical team requesting therapy for a child's mother. The social worker had been working with her for some time, but he felt worried by his client's depression and flight to another part of London. A team psychiatrist arranged to see the social worker the following day and review the case with him. The social worker kindly consented to the meeting being video-recorded and the tape was made available to the Workshop. The convenor stopped the tape at intervals for the Workshop to discuss how they might have proceeded had they been the consultant.

We learned the value of listening while a consultee is guided through the 'story' of his work, with occasional comments that summarise emerging patterns. It was then possible to suggest more realistic solutions to the current problem. In the above case it was for the social worker to contact a women's refuge counsellor in the other borough.

Consultation to a professional network

Some family problems can attract a considerable number of professionals, each trying to help in his own way. Unfortunately they may come to neutralise each other's efforts, or unwittingly undermine each other, and anxiety and confusion can resonate around the network (as in the Chinese Whispers party game). An opportunity to consult to the network and assist individuals co-ordinate their efforts can arise when the clinical team is requested to become yet another agency working with the family. ${ }^{4}$

The Workshop rehearsed management of these complex cases, in which it is essential to clarify background information about everybody else's role through a network meeting before being able to decide on any new intervention. We used the problem of school non-attendance, because these cases often become paralysed when workers side with opposing strategies-some favouring an authoritarian approach (e.g. Court proceedings) with others advocating a sympathetic one (e.g. therapy). The family may also contribute to indecision when the child (temporarily) returns to school a week or so before the Court hearing.

The convenor prepared for a Workshop meeting using material from a recent case of his, which had involved an educational psychologist, an education welfare officer a child guidance clinic social worker, a school teacher and a school medical officer as well as himself, a child psychiatrist. A vignette of each professional worker's involvement with the case was described on separate cards which were randomly handed around in the Workshop. Each participant was asked to use this information to play the role of a member of the network. The 'school medical officer' read out his (actual) referral letter to the 'child psychiatrist' (requesting a confidential report) who then had to role-play his case management and co-ordinate his role with the other 'workers'.

\section{THE REFERRAL}

Whose idea was it to contact me?

Who is asking me to do what to whom?

What is the nominated 'problem' for which this is the nominated 'solution'?

What alternative 'solutions' might there be?

What must I do?

\section{THE FAMILY}

The family life cycle story

The family's history of problems

To whom have they shown these problems?

Have any interventions made a difference?

What is the legal position?

\section{THE NETWORK}

Who else has been involved in the past?

For what reason?

What did they try to do?

With what results?

Who is involved now?

What are they doing?

Do they know of this referral?

What is their view of this referral?

\section{THE REFERRER}

How long has the referrer/the referrer's agency been involved?

How did this involvement begin?

What did the referrer/the referrer's agency do?

What has been the aim of this work?

How has it been going?

Are there changes pending in the referrer's agency?

\section{THE REFERRAL}

What are you hoping for from me?

Does anyone else have different expectations?

What will you/the network do if I am able to help in the way you have requested?

What will you/the network do if I am unable to help in the way you have requested?

FIG. 2. Map of a network 
Although such role plays may unfold differently from the actual case, participants gain a first-hand experience of being in a network that is underfunctioning. They are able to feed back their reactions and discuss what they might have done differently. We learned, for example, how essential it is for the chairperson to explain why he called the network meeting, and what he hopes to achieve (some definition about his future role); we also saw that he should facilitate the unfolding of the story of the case from all workers present.

The Workshop drew up a comprehensive series of questions which might, in different combinations, help the consultant map the wider system and understand its patterns of relationships (Fig. 2). This information guides him towards offering a new intervention that makes a difference to the case, instead of one which adds to the paralysis.

\section{Consultation to the staff of a unit}

Consultation to a unit usually occurs through a formal request to do so, or arises naturally from a clinical team's involvement with a number of cases referred over time by that unit. This mode of consultation is described well in the literature and the Workshop studied a number of texts. ${ }^{5}$ When a new request for consultation came to the clinical team we used a Workshop to construct a systemic map, and in other Workshops we reviewed participants' current consultation work.

Three members of the Workshop had consulted in turn to the hospital's Child Development Centre, and they offered to present their experiences to the Workshop. In reporting his work each was asked to emphasise how he had entered the Centre (how he had been invited, by whom, for what reason, etc) and how he had left it (the reason for termination, the Centre's response, how it was negotiated, etc).
We learned about our colleagues' successful contributions (e.g. instigating case discussions which helped the Centre co-ordinate their work) and some of their errors (e.g. failing to negotiate the original contract with the head of the Centre, and failing to clarify who was expected to attend the consultation meetings). We also were able to note how transitions in the life of a unit throw group phenomena into sharp relief, when they become available for understanding and resolution. For example, the Centre staff's low self esteem became exaggerated when one consultant left and they returned to a collective belief that people outside the Centre held the solutions to their challenging and difficult work. This false belief had to be made overt and questioned by the retiring consultant in order that his replacement could find a realistic role for himself.

\section{Comments}

Child psychiatrists may be called upon to consult in various ways, and a coherent training in consultation is considered essential for all registrars and senior registrars. Our multidisciplinary Workshop has helped all participants advance their knowledge and skill, and it has enhanced their work as a clinical team.

\section{REFERENCES}

${ }^{1}$ BAteson, G. (1972) Steps to an Ecology of Mind. New York: Ballantine.

${ }^{2}$ Dell, P. (1982) Family theory and the epistemology of Humberto Maturana. In The International Book of Family Therapy (Ed. F. W. Kaslow). New York: Brunner/Mazel.

${ }^{3}$ Selvini Palazzoli, M., Boscolo, L., Cecchin, G. \& Prata, G. (1980) Hypothesizing - circularity-neutrality: three guidelines for the conductor of the session. Family Process, 19, 3-12.

${ }^{4}$ REDER, P. (1986) Multi-agency family systems. Journal of Family Therapy, 8, 139-152.

${ }^{5}$ Selvini Palazzoli, M. (1986) The Hidden Games of Organizations. New York: Pantheon.

\section{The John Dunn Medal}

The Irish Journal of Psychological Medicine is offering the first John Dunn Medal for the best contribution accepted for publication in September 1988 or March 1989. The contribution may be an original article or brief report. One of the authors ought to be a trainee in Great Britain or Ireland. The first named trainee will receive the medal.
John Dunn, who was the first Professor of Psychiatry in Ireland and the President of the Royal MedicoPsychological Association, will present the first medal.

Enquiries to: Dr Mark Hartman, Editor, Irish Journal of Psychological Medicine, St Brendan's Hospital, PO Box 418, Rathdown Road, Dublin 7, Ireland. 